\title{
Estimation of Traffic Emissions in Suez Canal Road, Alexandria, Egypt
}

\author{
Sara A. Elgezary, Ali F. Bakr, and Mohamed A. Nasr
}

\begin{abstract}
The health risks of air pollution are extremely serious. Poor air quality increases respiratory ailments like asthma and bronchitis, heightens the risk of life-threatening conditions like cancer, and burdens our health care system with substantial medical costs. Particulate matter is singlehandedly responsible for up to 30,000 premature deaths each year. Passenger vehicles are a major pollution contributor, producing significant amounts of nitrogen oxides, carbon monoxide, and other pollution. In 2013, transportation contributed more than half of the carbon monoxide and nitrogen oxides, and almost a quarter of the hydrocarbons emitted into our air. Motor Vehicles are the main responsible for traffic emissions all over the world, this paper investigates traffic emissions in Suez Canal road in Alexandria, Egypt.
\end{abstract}

Keywords - Traffic - Emissions - Vehicles- Carbon monoxideCarbon dioxide- Particulate Matter.

\section{INTRODUCTION}

The relationship between vehicles and humans began with the invention of the wheel about 3000 BC. In the early 20th Century the introduction of assembly line techniques put the motor car within reach of many more people. Motor vehicles now include petrol and diesel-engined cars, motorcycles, light vans, passenger service vehicles (buses and coaches) and heavy goods vehicles (HGVs) [1]. The number of licensed vehicles on Egypt's roads rose by 12.2 percent year-over-year in 2014, recording 7.9 million nationwide, compared to 7.04 million in 2013, the Central Agency for Public Mobilization and Statistics (CAPMAS) said. According to CAPMAS's Bulletin of licensed vehicles 2014, Cairo is the governorate with the largest number of vehicles (2.2 million), followed by Giza $(921,500)$ and Alexandria $(702,100)$. The total number of licensed cars reached 4.1 million, 52.3 percent of the total amount of vehicles in 2014 . Most cars are private (3.7 million, 91.0 percent), while the remaining 7.8 percent were taxis $(322,100)$. Vehicles that consume gasoline ranked first, with 5.4 million vehicles, which corresponds to 70.5 percent of the total amount, followed by diesel users, with 4.7 million vehicles (21.9

Manuscript received October17, 2017

Sara A. Elgezary is a Phd student in the Faculty of Engineering, Alexandria, Egypt (e-mail: arc.sara.sara@gmail.com).

Ali F. Bakr is a professor in the Faculty of Engineering, Alexandria, Egypt, (e-mail: alibakr2000@gmail.com).

Mohamed A. Nasr is an assistant professor in the Faculty of Engineering, Alexandria, Egypt, (e-mail: targetwork@yahoo.com). percent) and gas users (628,500 vehicles - 9.1 percent)[2]. Vehicles emit carbon dioxide (CO2), carbon monoxide (CO), nitrogen oxides (NOx), hydrocarbons (HC), particulate matter (PM), hydrofluorocarbon 134a (HFC-134a), methane (CH4), and nitrous oxide (N2O) [3] . This paper studies and analysis the measurements of (co2),(co) and (PM) as part of traffic emissions for the total length of the axes (Suez Canal Road) in Alexandria, Egypt as an important local hotspot as it is the main entrance of Alexandria city.

\section{CASE STUDY}

\section{A. Devices:}

Two devices allowed in the environmental lab of Faculty of Engineering, Alexandria University were used in the measurements of the study in this paper which are:

- TSI 7545 IAQ-Calc CO2, CO2, Temp, Humidity, CO Meter / Data logger:

It simultaneously measures and data logs multiple parameters such as $\mathrm{CO}, \mathrm{CO}$, temperature and other parameters outside air.

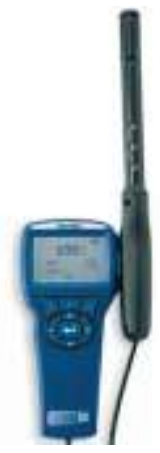

Fig. $1 \mathrm{CO}$ and $\mathrm{CO} 2$ Meter

- Fluke Fluke 985Particle counter, particle meter, air meter : It provides valuable data about the concentration and source of particles in the test environment.

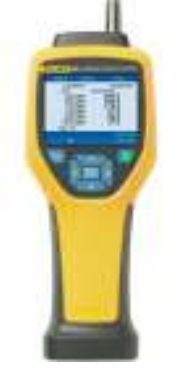

Fig.2 PM Meter 


\section{B. Measurements:}

The following measurements were taken in April, 2017.

- Day Measurements:

TABLE-1 DAY MEASUREMENTS

\begin{tabular}{|c|c|c|c|c|c|c|}
\hline & & & & SusI & ended Par & cles \\
\hline Point No. & Time & $\mathrm{Co2}$ & $\mathrm{C}_{0}$ & $\begin{array}{l}0.3 \\
E+7 / \mathrm{m} 3\end{array}$ & $\begin{array}{l}0.5 \\
\mathrm{E}+7 / \mathrm{m} 3\end{array}$ & $\begin{array}{l}5 \\
\mathrm{E}+5 / \mathrm{m} 3\end{array}$ \\
\hline point 1 & $12: 10: 00$ & 427 & 1 & 5.26 & 1.64 & 1.75 \\
\hline point 2 & $12: 45: 00$ & 419 & 2 & 3.45 & 1.12 & 3.04 \\
\hline point 3 & $12: 50: 00$ & 444 & 2 & 5.32 & 2.2 & 1.35 \\
\hline point 4 & $12: 20: 00$ & 438 & 2 & 4.08 & 1.13 & 1.26 \\
\hline point 5 & $12: 30: 00$ & 577 & 7 & 6.18 & 2.66 & 6.14 \\
\hline point 6 & $12: 40: 00$ & 456 & $I$ & 5.73 & 1.73 & 4.72 \\
\hline point 7 & $13: 00: 00$ & 502 & 3 & 2.57 & 0.85 & 5.99 \\
\hline point 8 & $13: 45: 00$ & 583 & 1 & 4.63 & 2.34 & 1.37 \\
\hline point 9 & $13: 55: 00$ & 523 & 3 & 3.27 & 1.54 & 1.22 \\
\hline Point 10 & $14: 05: 0$ & 407 & 2 & 3.57 & 8.17 & 1.31 \\
\hline Point 11 & $14: 15: 0$ & 480 & 3 & 3.48 & 9.14 & 9.25 \\
\hline
\end{tabular}

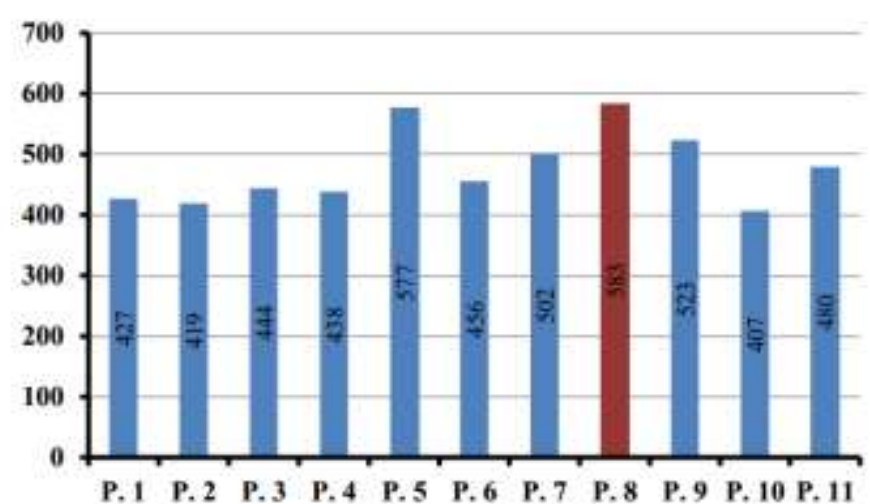

Fig.3 Carbon Dioxide Readings Chart.

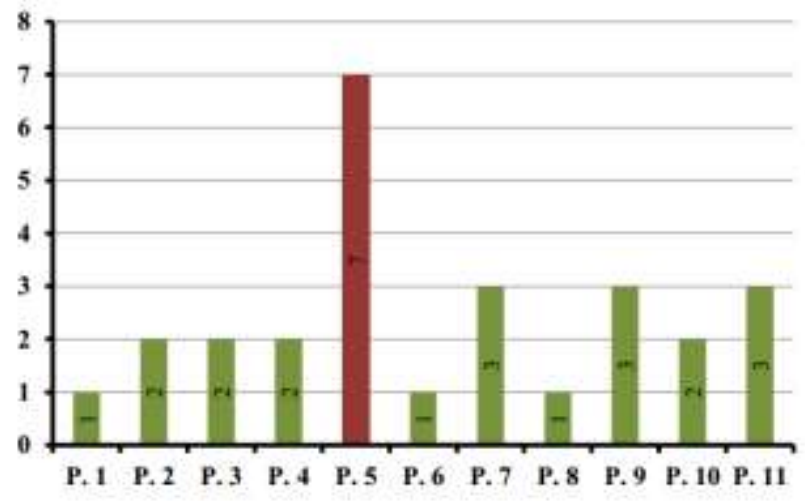

Fig.4 Carbon Monoxide Readings Chart.

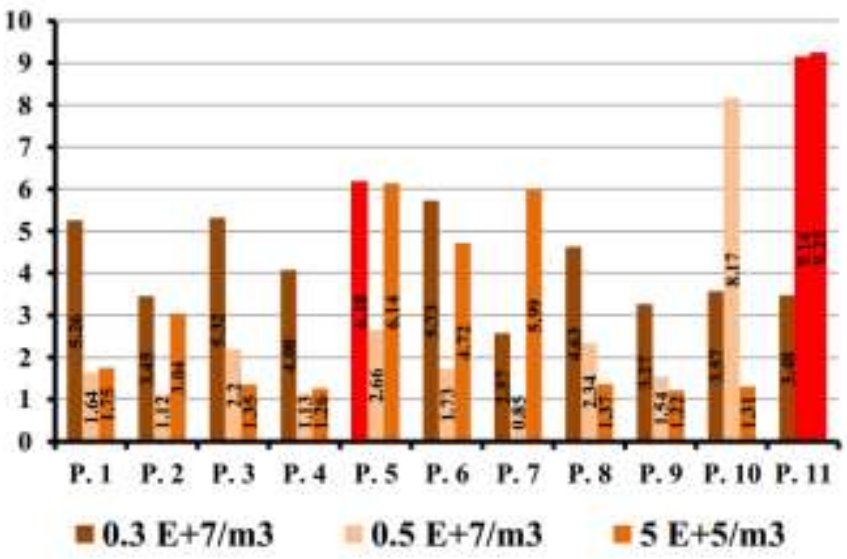

Fig.5 Particles Matter Readings Chart.

- Night Measurements:

\begin{tabular}{|c|c|c|c|c|c|c|}
\hline \multicolumn{7}{|c|}{ Suspended Particles } \\
\hline Point No. & Time & $\mathrm{C}_{02}$ & $C_{0}$ & $\begin{array}{c}0.3 \\
\mathrm{E}+7 / \mathrm{m}^{3}\end{array}$ & $\begin{array}{c}0.5 \\
E+7 / \mathrm{ms}^{3}\end{array}$ & $\begin{array}{c}5 \\
\mathrm{E}+5 / \mathrm{m} 3\end{array}$ \\
\hline point 1 & $20: 30 \cdot 00$ & 460 & 2 & 5.33 & 1.09 & 1.26 \\
\hline point 2 & $20: 48: 00$ & 580 & $y$ & 5.12 & 1.04 & 1.2 \\
\hline point 3 & $20: 54: 00$ & 505 & 8 & 4.82 & 1.18 & 1.12 \\
\hline poiat 4 & $21: 11: 00$ & 451 & $I$ & 5 & 1.23 & 1.36 \\
\hline point 5 & $21: 20: 00$ & 612 & If & 5.98 & 2.53 & 5.36 \\
\hline point 6 & $21: 24: 00$ & 511 & 3 & 6.11 & 2.01 & 5.84 \\
\hline poiat 7 & 21.30 .00 & 474 & 3 & 5.88 & 2.19 & 3.55 \\
\hline point 8 & $21: 41: 00$ & 523 & 9 & 5,55 & 2.73 & 282 \\
\hline point 9 & $21: 45: 00$ & $3 / 3$ & 3 & 6.02 & 2.08 & 5,4 \\
\hline Poiat 10 & 21:57:00 & 495 & 2 & 6.15 & 2.25 & 5.19 \\
\hline Poiat 11 & 22:05:00 & 468 & 2 & 5,97 & 2.29 & 6.32 \\
\hline
\end{tabular}

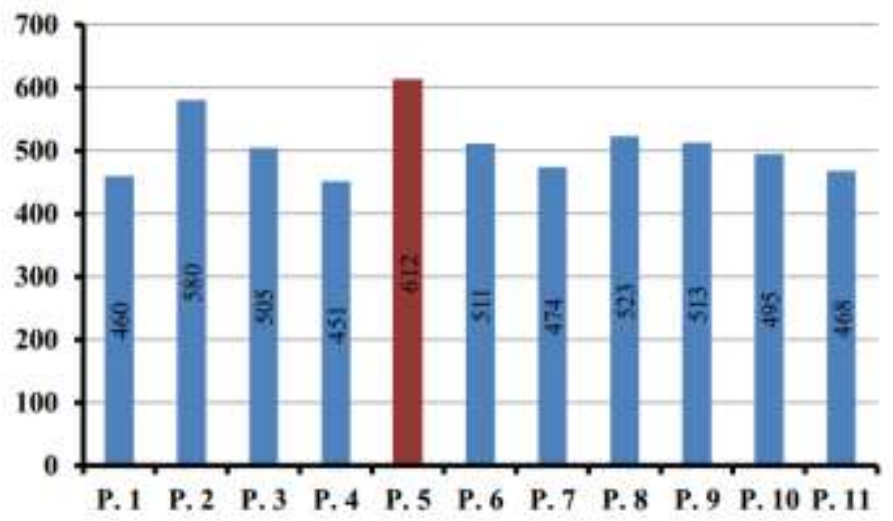

Fig.6 Carbon Dioxide Readings Chart. 


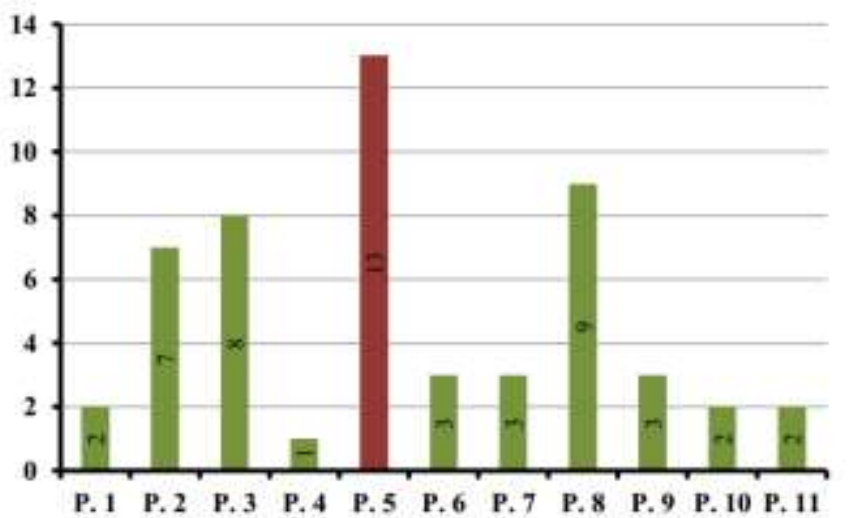

Fig.7 Carbon Monoxide Readings Chart

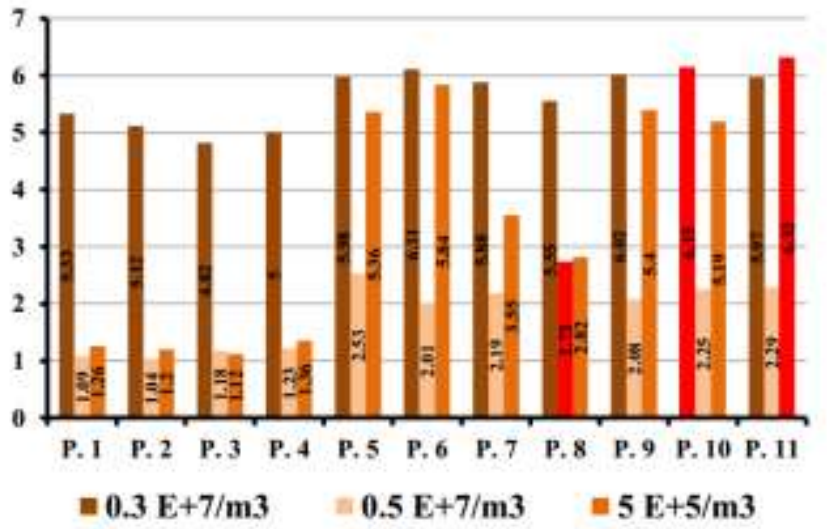

Fig.8 Particle Matter Readings Chart.

- Day/Night Comparative Analysis:

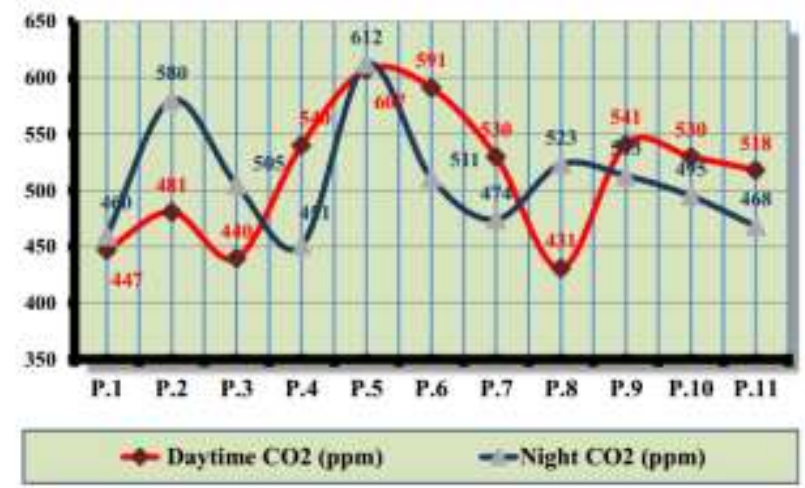

Fig-9 Average Day and Night Carbon dioxide chart.

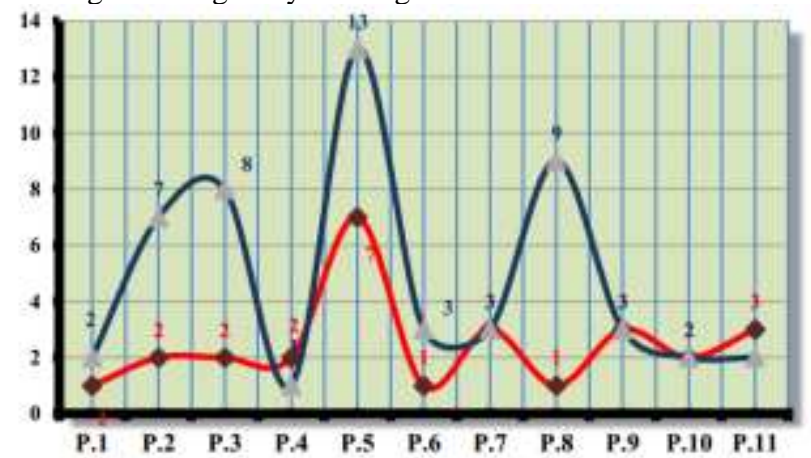

Daytime CO (ppm)

$$
\text { --Night CO (ppm) }
$$

Fig.10 Average Day and Night Carbon Monoxide Chart.

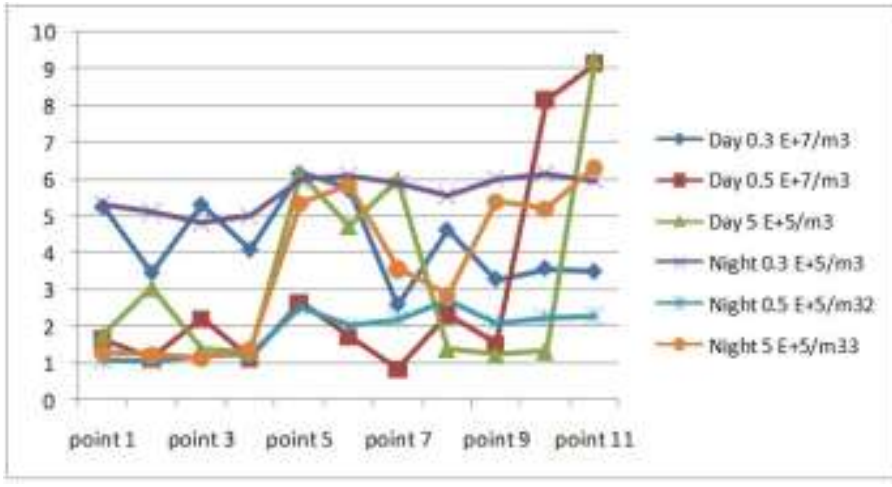

\section{C.Measurements Analysis}

From the previous measurements it's obvious that Co and $\mathrm{Co} 2$ are most concentrated in Point 5 (Suez Canal Tunnel) which is shown in Figure 12 and PM is mostly concentrated in Point 11 ( the entrance of Suez Canal Road from the Desert Road) as shown in figure 12 .

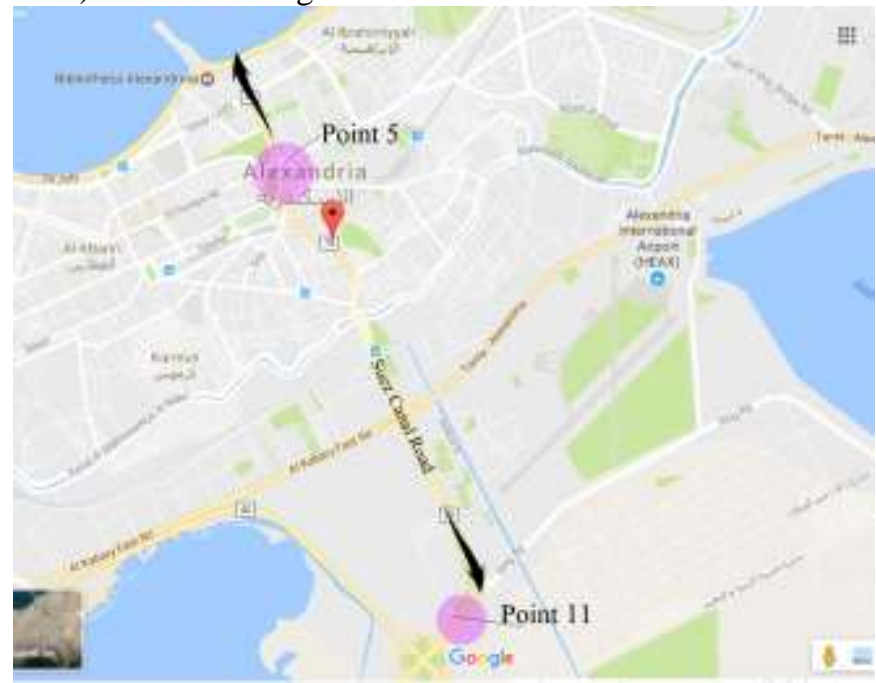

Fig.12 Map of Suez Canal Road

\section{CONCLUSION}

From the comparative study of Day and Night measurements, the researcher has realized that Suez Canal Road is considered a healthy road according to co ,co2 and PM comfort levels[4] [5], except for point 5 for co and co2 and point 11 for PM. There is a need for more research, but also a need to begin to explore policy options that would protect the exposed population near polluted points. 


\section{ACKNOWLEDGMENT}

I would like to thank Prof. Dr. Ali F. Bakr for his constructive advice and encouragement throughout this paper and for his continued support and motivation. I would like to thank Prof. Dr. Mohamed Abdelaal, Ass. Prof. Zeyad Elsayad and my colleagues in $\mathrm{PhD}$ group for their efforts in collecting measurements in $\mathrm{PhD}$ courses.

\section{REFERENCES}

[1] (2017). Retrieved 13 April 2017, from http://www.airquality.org.uk/08.php

[2] (2017). Retrieved 1 May 2017, from http://www.capmas.gov.eg/

[3] (2017).Retrieved2May2017,from http://www.umtri.umich.edu/ourresults/publications/emissions-co2-co-nox-hc-pm-hfc-134a-n2o-and-ch4global-light-duty-vehicle

[4] TheEngineeringToolBox. (N/A). Carbon Dioxide Comfort Levels. Retrieved from the Engineering ToolBox: http://www.engineeringtoolbox.com/co2-comfort-level-d_1024.html

[5] NCSU.(N/A). Air Quality. Retrieved from State Climate Office of North Carolina: http://www.hatteras.meas.ncsu.edu/climate/aq 